\title{
Chitosan-Coated Titanium Dioxide-Embedded Paclitaxel Nanoparticles Enhance Anti-Tumor Efficacy Against Osteosarcoma
}

\section{OPEN ACCESS}

Edited by:

Luis Alexandre Muehlmann, University of Brasilia, Brazil

Reviewed by: Yasuhiro Hayakawa, Shizuoka University, Japan Davood Ghanbari, Arak University of Technology, Iran

Correspondence:

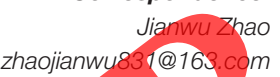
31@168.com

Specialty section

This article was submitted to Cancer Molecular Targets

and Therapeutics,

a section of the journal

Frontiers in Oncology

Received: 29 June 2020

Accepted: 17 August 2020 Published: 09 September 2020

Citation:

Qu Y, Kang M, Cheng X and Zhao J (2020) Chitosan-Coated

Titanium Dioxide-Embedded Paclitaxel Nanoparticles Enhance

Anti-Tumor Efficacy Against Osteosarcoma

Front. Oncol. 10:577280 doi: $10.3389 /$ fonc. 2020.577280
Yang Qu, Mingyang Kang, Xueliang Cheng and Jianwu Zhao*

Department of Orthopedics, The Second Hospital of Jilin University, Changchun, China

Objective: Titanium dioxide nanoparticles $\left(\mathrm{TiO}_{2}\right)$ nanoparticles have been widely explored in the prevention of cancer risk. Due to the difficult solubility of $\mathrm{TiO}_{2}$ nanoparticles, it is essential to synthesize new suffactants to increase its bioavailability and anti-tumor activity and reduce its cytotoxicity. Furthermore, oxidative and inflammation are closely associated with the osteosarcoma risk. Chitosan has biocompatibility, antioxidant and anti-inflammatory properties. The effects of chitosan-coated $\mathrm{TiO}_{2}$-embedded paclitaxel nanoparticles on an osteosarcoma model were explored.

Methods: An osteosarco embedded paclitaxel nanoparticles were prepared using a freeze-drying strategy. The morphological characteristics of nanoparticles were observed using scanning electron microscopy (SEM). The physicochemical properties of nanoparticle were evaluated by $X$-ray diffraction $(X R D)$ and Fourier transform infrared (FTIR) spectroscopy. The cytatoxicity was tested by using human osteoblast cells hFob1.19 and osteosarcoma cells $143 \mathrm{~B}$. Osteosarcoma mice were treated with PBS buffer, paclitaxel, $\mathrm{TiO}_{2}-$ embedded paclitaxel and chitosan-coated $\mathrm{TiO}_{2}$-embedded paclitaxel nanoparticles. The biomarkers of oxidative-inflammatory status, anti-tumor activities and survival rates of the model were measured.

Results: XRD analysis showed that the peaks of chitosan $/ \mathrm{TiO}_{2}$ (anatase) were consistent with those of crystalline $\mathrm{TiO}_{2}$ and broad phase of chitosan. The FTIR spectrum indicated the relevant functional groups in $\mathrm{TiO}_{2}$. Chitosan-coated $\mathrm{TiO}_{2}-$ embedded paclitaxel nanoparticles had good biocompatibility and improve antioxidant and anti-inflammatory properties in the osteosarcoma model. Chitosan-coated $\mathrm{TiO}_{2}-$ embedded paclitaxel nanoparticles was less toxic to the cells hFob1.19 and more toxic to the cells $143 \mathrm{~B}$ than $\mathrm{TiO}_{2}$-embedded paclitaxel nanoparticles. Chitosan-coated $\mathrm{TiO}_{2}-$ embedded paclitaxel nanoparticles showed significant antitumor activity and increased the survival rate of the osteosarcoma model $(P<0.05)$.

Conclusions: Chitosan improved anti-tumor potential of $\mathrm{TiO}_{2}$-embedded paclitaxel nanoparticles in the prevention of osteosarcoma.

Keywords: osteosarcoma, titanium dioxide nanoparticles, chitosan, antioxidant, anti-inflammatory, anti-tumor, survival rate 


\section{INTRODUCTION}

Osteosarcoma is the leading cause of bone malignancy (1) and one of the important causes of death and disability worldwide $(2,3)$. The disease is a common emergency in bone surgery and should be early diagnosed and treated to obtain a better prognosis. Titanium dioxide $\left(\mathrm{TiO}_{2}\right)$ nanoparticles are potential materials in the prevention of osteosarcoma and chondrosarcoma recurrence (4). Paclitaxel, classified as a "plant alkaloid," is isolated originally from the bark of Taxus brevifolia and has been widely reported in the treatment of osteosarcoma $(5,6)$. $\mathrm{TiO}_{2}$-embedded paclitaxel nanoparticles have been tried in the prevention of cancer risk (7). However, due to the difficult solubility of paclitaxel, it is essential to explore new forms to increase its bioavailability and anti-tumor activity and reduce toxicity $(8,9)$.

Chitosan, a promising natural polysaccharide and the derivative of chitin, is used as a friendly biomaterial in tissue engineering because of its biocompatibility and easy degradation without toxicity $(10,11)$. Chitosan polymeric micelles have been developed for improving the bioavailability of paclitaxel and reducing its toxicity (12-14). However, chitosan has various disadvantages, such as weak mechanical strength $(15,16)$ and fast degradation (17). $\mathrm{TiO}_{2}$ is available in nanocrystals with wide surface area and has antibacterial activity (18). $\mathrm{TiO}_{2}$ has been used as good material in medical and health applications due to its inert property (19). Chitosan molecules can be assembled through hydrophobic interaction and hydrogen binding (20) Both chitosan and $\mathrm{TiO}_{2}$ are biocompatible, inert, and chemically stable so that they may be beneficial in the prevention of osteosarcoma progression.

Oxidative stress often induces osteosarcoma cell invasion, migration, and the epithelial-to-mesenchymal transition through the miR-153/snail family zinc finger 1 axis (21). Furthermore, pretreatment inflammatory index neutrophil-lymphocyte patio is associated with the poor outcomes in patients (22). Thus, the antioxidant and anti-inflammatory therapy is a potential approach in the prevention of the progression and development of osteosarcoma $(23,24)$. Fortunately, the antioxidant and antiinflammatory properties of chitosan have been widely reported $(25,26)$.

The purpose of this study is to compare the properties of chitosan-coated $\mathrm{TiO}_{2}$-embedded paclitaxel nanoparticles and $\mathrm{TiO}_{2}$-embedded paclitaxel nanoparticles and analyze the effects of chitosan in the prevention of osteosarcoma development.

\section{MATERIALS AND METHODS}

\section{Synthesis of Chitosan-Coated $\mathrm{TiO}_{2}$-Embedded Paclitaxel and $\mathrm{TiO}_{2}$-Embedded Paclitaxel Nanoparticles}

Low-molecular-weight chitosan $(80 \%$ deacetylated $)$ was purchased from Aokang Biotech Co., China. $\mathrm{TiO}_{2}$-embedded paclitaxel nanoparticles were purchased from Grikin (Beijing, China). $\mathrm{TiO}_{2}$-embedded paclitaxel nanoparticles were synthesized by using grafting folic acid for targeted paclitaxel onto $\mathrm{TiO}_{2}$ as nanocarrier. Different concentrations of chitosan acetic acid hydrosol was prepared by the dissolution of 20,40,

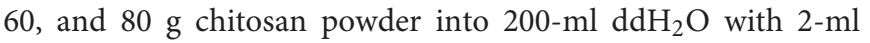
acetic acid. Chitosan in an acidic solution was sprayed and dispersed via a spray drying technology, and then sprayed in a hot gas stream to rapidly form chitosan-coated $\mathrm{TiO}_{2}$-embedded paclitaxel nanoparticles.

\section{SEM Observation}

Scanning electron microscopy (SEM) is a common technique to characterize the morphology, and size of nanoparticles (27-31), and was conducted on JEOL JSM 5900LV [JEOL (Beijing) Co., Ltd., Beijing, China]. SEM showed morphological characteristics of $\mathrm{TiO}_{2}$-embedded paclitaxel and chitosan-coated $\mathrm{TiO}_{2}$-embedded paclitaxel nanoparticles. For the SEM analysis, the nanoparticles were covered with gold coating and observed via the Scanning Electroscope JEOL JSM 5900LV. Meanwhile, the microstructure of two kinds of nanoparticles was examined with SEM. The Energy Dispersive X-Ray Spectroscopy (EDS) spectra were developed using JEOL SEM $(20 \mathrm{kV})$.

\section{XRD Analysis}

$\mathrm{X}$-ray diffraction (XRD) has become a routine method to measure the structure and phase and crystallinity and purity of nanoparticles (27-32). The structure and phase $\mathrm{TiO}_{2}$ and chitosan-coated $\mathrm{TiO}_{2}$ nanoparticles were characterized by XRD. The diffraction pattern of $\mathrm{TiO}_{2}$ sample was indexed by comparing with the anatase $\mathrm{TiO}_{2}$ and rutile $\mathrm{TiO}_{2}$ standards from Sigma-Aldrich and the Joint Committee on Powder Diffraction Standards (JCPDS) Card File No. 21-1272 and 211276 (33). The graphical X-ray powder diffraction patterns of the $\mathrm{TiO}_{2}$-embedded paclitaxel and chitosan-coated $\mathrm{TiO}_{2}$-embedded paclitaxel samples were observed by using Ultima IV X-ray diffractometer (Rigaku, Woodlands, TX, United States), using $\mathrm{Cu}-\mathrm{Ka}(1.5 \AA)$ in the range of $20^{\circ}$ to $60^{\circ}$ at $2 \theta$ degree. XRD analysis was adjusted according to the anatase $\mathrm{TiO}_{2}$ and rutile $\mathrm{TiO}_{2}$ standards.

\section{FTIR Analysis}

FTIR spectra (from 4,000 to $500 \mathrm{~cm}^{-1}$ ) of the surface of $\mathrm{TiO}_{2}$-embedded paclitaxel and chitosan-coated $\mathrm{TiO}_{2}$-embedded paclitaxel nanoparticles were measured in Perkin Elmer Spectrum RX1 spectrometer (Canton, MA, United States). FTIR showed the related functional groups in the molecules.

\section{MTT [3-(4,5-Dimethylthiazol-2-yl)-2, 5-Diphenyltetrazolium Bromide] Analysis of the Toxicity of Chitosan-Coated $\mathrm{TiO}_{2}$-Embedded Paclitaxel and $\mathrm{TiO}_{2}$-Embedded Paclitaxel Nanoparticles}

The human osteoblast cells hFob1.19 and osteosarcoma cells 143B were purchased from the cell bank of Shanghai Institutes for Biological Sciences (Shanghai, China) and cultured in DMEM medium (Gibco, Shanghai, China) supplemented with 10\% heat-inactivated FBS (Hyclone, Shanghai, China), $100 \mu \mathrm{g} / \mathrm{mL}$ 
of penicillin and $100 \mu \mathrm{g} / \mathrm{mL}$ of streptomycin (Yuanmu Biotechnology Co., Ltd., Shanghai, China). All cells were cultured at $37^{\circ} \mathrm{C}$ in a $5 \% \mathrm{CO}_{2}$ atmosphere. The culture temperature of hFob1.19 cell was $33.5^{\circ} \mathrm{C}$, and $143 \mathrm{~B}$ cell was $37^{\circ} \mathrm{C}$. The cells were transferred into a 96-well plate at a cell density of $1 \times 10^{4}$ cells/well with $5 \% \mathrm{CO}_{2}$. After culturing for $24 \mathrm{~h}, 50 \mu \mathrm{L}$ of different concentrations of paclitaxel, chitosan-coated $\mathrm{TiO}_{2}$ embedded paclitaxel or $\mathrm{TiO}_{2}$-embedded paclitaxel nanoparticles were added after the cells fully adhered. The final concentration gradients of paclitaxel were $0.36,0.725,0.15,0.31,0.625,1.25$, $2.5,5$, and $10 \mu \mathrm{g} / \mathrm{mL}$. The 96-well plate was placed in the cell incubator and continued to be incubated for $72 \mathrm{~h}$, and then $20 \mu \mathrm{L}$ of pre-configured MTT (Sigma-Aldrich, St. Louis, MO, United States) PBS solution was added to each well and continued to be incubated for $4 \mathrm{~h}$. Subsequently, the medium in each well was carefully removed and $200 \mu \mathrm{L}$ of DMSO was added and shaken for $10 \mathrm{~min}$ to completely dissolve the blueviolet formazan. Finally, the absorbance value (A) at $490 \mathrm{~nm}$ was measured with a microplate reader to calculate the cell survival rate. Cell viability was calculated as follows: (OD values in experimental wells-OD values in blank wells)/(OD values in control wells - OD values in blank wells) $\times 100$.

\section{Animal Grouping and Establishment of Osteosarcoma Model}

Before the experiments, all procedures were approved by the animal research ethics committee of The Second Hospital of Jilin University (Approval No. 2019JLU23D). Forty-eight female BALB-c nude mice (4 weeks, 18-22 g) were purchased from the animal center of Jilin University (Changchun, China) and randomly divided into four groups on average: control group (PBS solution, CG), experimental group chitosan-coated $\mathrm{TiO}_{2}$-embedded paclitaxel $(5 \mathrm{mg} / \mathrm{kg}$ ) nanoparticles (PGTG), paclitaxel (PG, $5 \mathrm{mg} / \mathrm{kg}), \mathrm{TiO}_{2}$-embedded paclitaxel $(5 \mathrm{mg} / \mathrm{kg})$ nanoparticles (PTG), first adapt to the environment and trained for 2 weeks. Nude mice were anesthetized by intraperitoneal ketamine/xylazine (100 mg per kg/10 mg per kg) (34). After the nude mice enter anesthesia, follow-up operations are performed. After anesthetizing nude mice, $50 \mu \mathrm{L} 1 \times 10^{7}$ cells $/ \mathrm{mL} 143 \mathrm{~B}$ luc suspension was injected into the proximal tibia of each nude mouse with a 25-G needle. After the tumor cells were inoculated, each nude mouse was randomly checked for tumor formation in the tibia of the left lower limb. Osteosarcoma is relatively deep, so it is impossible to determine whether a tumor has formed by visual inspection and touch. $143 \mathrm{~B}$ cells can generally form tumors in situ in 2 weeks, and the positive fluorescence signal in live imaging is the standard for tumor formation.

\section{Measurement of Markers of Oxidative-Inflammatory Status}

A sample of $0.5 \mathrm{ml}$ of blood was obtained from the mouse tail vein. The serum was prepared via centrifugation at $2,000 \times g$ for $10 \mathrm{~min}$ and stored at $-20^{\circ} \mathrm{C}$ for ELISA measurement. Serum tumor necrosis factor $\alpha(\mathrm{TNF} \alpha)$ (ab208348), interleukin (IL)-1 $\beta$ (ab100705), IL-6 (ab222503) and IL-10 (ab255729) were examined using the ELISA kits from Abcam (Cambridge,
MA, United States). Serum superoxide dismutase (SOD) (MBS034842) and catalase (CAT) (MBS704962), glutathione peroxidase (GSPx) (MBS723759) and MDA (MBS741034) were determined using the kits from MyBioSource, Inc. (Vancouver, WA, United States). All these biomarkers were measured on an automatic chemical analyzer (CliniTek 500, Bayer, United States).

\section{In vivo Imaging of Osteosarcoma}

After 14-day tumor cell inoculation, different groups of nude mice were treated with PBS buffer, paclitaxel, chitosan-coated $\mathrm{TiO}_{2}$-embedded paclitaxel nanoparticles or $\mathrm{TiO}_{2}$-embedded paclitaxel nanoparticles, respectively. The dose of paclitaxel was $5 \mathrm{mg} / \mathrm{kg}$ in the 3 latter groups (35). Subsequently, nude mice received in situ tumor injection treatment twice a week. On days 14,21 , and 28 , live imaging was performed on nude mice and fluorescein was injected before 5-min imaging. The nude mice were anesthetized after 15-20 min of activity, and placed in the prone position in the imaging detection system. In the statistical analysis, the tumor bioluminescence intensity was normalized to the initial amount of fluorescence intensity on the 14th day of each nude mouse.

\section{Tumor Mass}

After 28 days of tumor cell inoculation, the nude mice of each group were inraged in vivo. The nude mice were sacrificed, osteosarcoma tissue was dissected, washed with PBS, and cleaned with filter paper. The tumor mass was evaluated among different groups.

\section{Survival Curve of the Mice}

To investigate the survival curves of the nude mice of the control group (PBS solution) and the experimental groups, in situ injection therapy was performed twice a week after 2 weeks of injection of 143B cells. During the treatment, the survival rate was calculated every week for 10 weeks among another four groups: control group (PBS solution, CG), experimental group chitosan-coated $\mathrm{TiO}_{2}$-embedded paclitaxel $(5 \mathrm{mg} / \mathrm{kg}$ ) nanoparticles (PCTG), paclitaxel (PG, $5 \mathrm{mg} / \mathrm{kg}$ ), and $\mathrm{TiO}_{2}$ embedded paclitaxel $(5 \mathrm{mg} / \mathrm{kg}$ ) nanoparticles (PTG).

\section{Statistical Analysis}

The data were presented as mean values \pm standard deviation (SD). The normal distribution was analyzed using the ShapiroWilk test and a two-tailed Student's $t$-test was used to compare the significance of two groups. The count data were analyzed by a chi-square test. $P<0.05$ was considered statistically significant.

\section{RESULTS}

\section{Morphologic Characters of Chitosan Nanoparticles}

The maps of all samples were shown in Supplementary Figure S1. SEM showed that $\mathrm{TiO}_{2}$-embedded paclitaxel nanoparticles were spherical and the diameter of $\mathrm{TiO}_{2}$-embedded paclitaxel nanoparticles ranged from 40 to $60 \mathrm{~nm}$ (Figures 1a,b). EDS was used to characterize the elemental composition of 

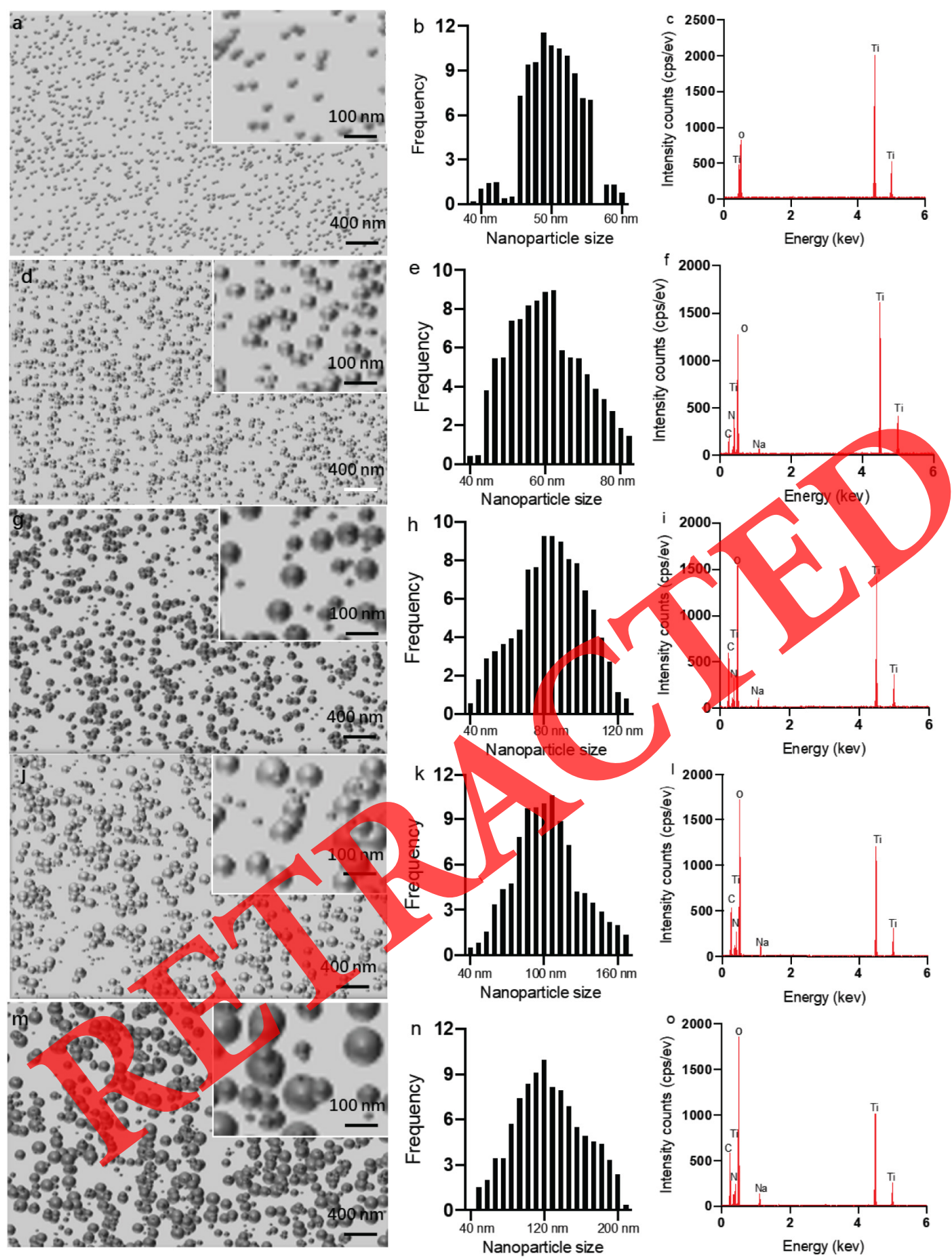

FIGURE 1 | Scanning electron microscopy (SEM) analysis of $\mathrm{TiO}_{2}$-embedded paclitaxel nanoparticles and chitosan-coated TiO 2 nanoparticles. (a) Micrograph of $\mathrm{TiO}_{2}$-embedded paclitaxel nanoparticles powder. (b) The size of $\mathrm{TiO}_{2}$-embedded paclitaxel nanoparticles powder. (c) Energy Dispersive X-Ray Spectroscopy (EDS) spectra for the $\mathrm{TiO}_{2}$ nanoparticle composite. (d) Micrograph of $1 \%$ chitosan-coated $\mathrm{TiO}_{2}$ oligosaccharides powder. (e) The size of $1 \%$ chitosan-coated $\mathrm{TiO}_{2}$-embedded paclitaxel nanoparticles powder. (f) EDS spectra for $1 \%$ chitosan-coated $\mathrm{TiO}_{2}$-embedded paclitaxel nanoparticles powder. (g) Micrograph of $2 \%$ chitosan-coated $\mathrm{TiO}_{2}$ oligosaccharides powder. (h) The size of $2 \%$ chitosan-coated $\mathrm{TiO}_{2}$-embedded paclitaxel nanoparticles powder. (i) EDS spectra for $2 \%$ chitosan-coated $\mathrm{TiO}_{2}$-embedded paclitaxel nanoparticles powder. (j) Micrograph of 3\% chitosan-coated $\mathrm{TiO}_{2}$ oligosaccharides powder. (k) The size of $3 \%$ chitosan-coated $\mathrm{TiO}_{2}$-embedded paclitaxel nanoparticles powder. (I) EDS spectra for 3\% chitosan-coated TiO $\mathrm{T}_{2}$-embedded paclitaxel nanoparticles powder. (m) Micrograph of $4 \%$ chitosan-coated $\mathrm{TiO}_{2}$ oligosaccharides powder. (n) The size of $4 \%$ chitosan-coated TiO $\mathrm{C}_{2}$-embedded paclitaxel nanoparticles powder. (o) EDS spectra for $4 \%$ chitosan-coated $\mathrm{TiO}_{2}$-embedded paclitaxel nanoparticles powder. 
chitosan-coated $\mathrm{TiO}_{2}$ nanoparticles prepared by using different concentration of chitosan. In the $\mathrm{TiO}_{2}$ nanoparticles, the main elements $\mathrm{O}$ and $\mathrm{Ti}$ were observed (Figure 1c), which were consistent with the main elements of $\mathrm{TiO}_{2}$ nanoparticle. SEM of chitosan-coated $\mathrm{TiO}_{2}$-embedded paclitaxel nanoparticles with the size from 40 to $200 \mathrm{~nm}$ presented a spherical shape with some irregular shapes. With the increase in the concentration of chitosan, the size of nanoparticles increased. The diameter ranged from 40 to $80 \mathrm{~nm}$ for $1 \%$ chitosan-coated $\mathrm{TiO}_{2}$-embedded paclitaxel nanoparticles (Figures 1d,e), from 40 to $120 \mathrm{~nm}$ for $2 \%$ chitosan-coated $\mathrm{TiO}_{2}$-embedded paclitaxel nanoparticles (Figures 1g,h), from 40 to $160 \mathrm{~nm}$ for $3 \%$ chitosan-coated $\mathrm{TiO}_{2}$ embedded paclitaxel nanoparticles (Figures $\mathbf{1 j}, \mathbf{k}$ ), and from 40 to $200 \mathrm{~nm}$ for $4 \%$ chitosan-coated $\mathrm{TiO}_{2}$-embedded paclitaxel nanoparticles (Figures 1m,n). Large particles made a smooth area but the higher concentration of chitosan became difficult to be dissolved. Thus, $4 \%$ chitosan was used for the preparation of nanoparticles. The microstructure of nanoparticles was similar between non-coated and chitosan-coated ones. In the chitosancoated $\mathrm{TiO}_{2}$ nanoparticles, the main elements $\mathrm{C}, \mathrm{N}, \mathrm{O}, \mathrm{Na}$, and Ti were observed (Figures $\mathbf{1 f}, \mathbf{i}, \mathbf{l}, \mathbf{o}$ ), which were consistent with the main elements of chitosan-coated $\mathrm{TiO}_{2}$ nanoparticle.

\section{Characterization of Chitosan-Coated $\mathrm{TiO}_{2}$-Embedded Paclitaxel Nanoparticles and $\mathrm{TiO}_{2}$ Nanoparticles}

XRD analysis showed that the phase of $\mathrm{TiO}_{2}$ was the same as that of anatase $\mathrm{TiO}_{2}$ standard and JCPDS No. 21-1272. Thus, anatase $\mathrm{TiO}_{2}$ was used in the present nanoparticles. The peaks of chitosan-coated $\mathrm{TiO}_{2}$-embedded paclitaxel nanoparticles and $\mathrm{TiO}_{2}$-embedded paclitaxel nanoparticles at $25.1^{\circ}, 36.9^{\circ}$, $37.9^{\circ}, 38.8^{\circ}, 48.0^{\circ}, 54.0^{\circ}$, and $55.0^{\circ}$ corresponding to $\mathrm{TiO}_{2}$ (crystalline) and broad phase $30.0^{\circ}, 36.0^{\circ}, 43.4^{\circ}, 545^{\circ}$ and $58.0^{\circ}$ corresponding to chitosan (Figure $2 \mathrm{~A}$ ). The results suggest that chitosan has excellent physiochemical properties such as biocompatible.

The FTIR spectrum indicated the relevant functional groups in chitosan-coated $\mathrm{TiO}_{2}$-embedded paclitaxel nanoparticles and $\mathrm{TiO}_{2}$-embedded paclitaxel nanoparticles (Figure 2B). There was a band present from 3,350 to $3,600 \mathrm{~cm}^{-1}$ because of $\mathrm{OH}$ vibrations. The band presented from 500 to $891 \mathrm{~cm}^{-1}$ for Ti-OTi vibrations, $1,630 \mathrm{~cm}^{-1}$ showed Ti-OH vibrations because of adsorbed $\mathrm{H}_{2} \mathrm{O}$ and $1,380 \mathrm{~cm}^{-1}$ indicated Ti-O. The functional groups $\mathrm{C}-\mathrm{H}$ and $\mathrm{C}=\mathrm{O}$ were detected at peaks 2,942 and $1,656 \mathrm{~cm}^{-1}$, respectively.

\section{MTT Cytotoxicity Evaluation}

The cytotoxicity of nanoparticles and paclitaxel was evaluated by the MTT method. As shown in Figure $\mathbf{3 A}$ for the human osteoblast cell line hFob1.19, with the increase in the concentration of paclitaxel, $\mathrm{TiO}_{2}$-embedded paclitaxel and chitosan-coated $\mathrm{TiO}_{2}$ nanoparticles, the cytotoxicity was enhanced. When the drug concentration was more than $10 \mu \mathrm{g} / \mathrm{mL}$, the cell survival rate was still more than $80 \%$, which was between $\mathrm{TiO}_{2}$-embedded paclitaxel and chitosancoated $\mathrm{TiO}_{2}$ nanoparticles. In the present study, the paclitaxel

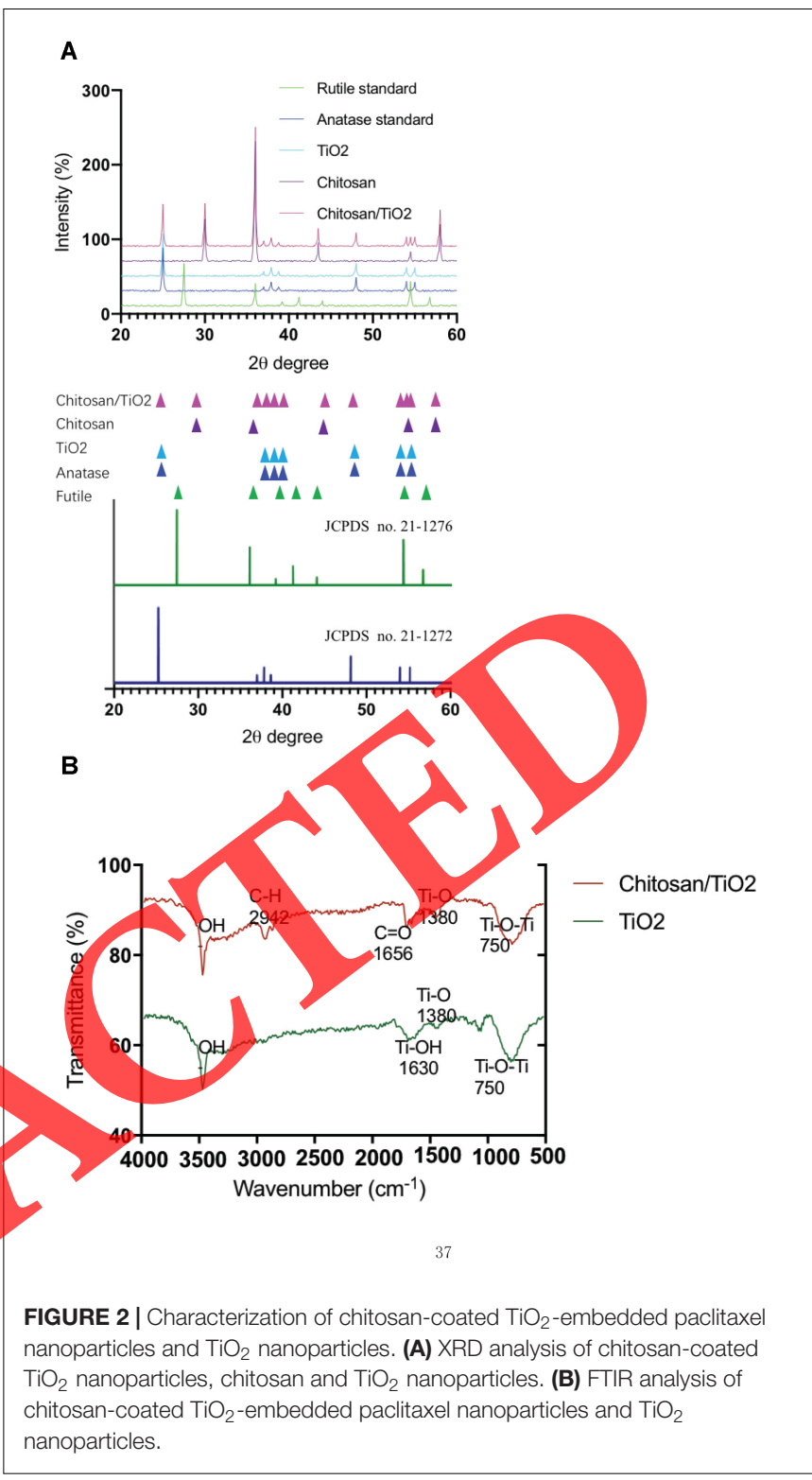

concentration $5 \mu \mathrm{g} / \mathrm{mL}$ ( $5 \mathrm{mg} / \mathrm{kg}$ ) was selected to be used in the model. As shown in Figure 3B, for the human osteosarcoma cell line (143B), paclitaxel, $\mathrm{TiO}_{2}$-embedded paclitaxel and chitosancoated $\mathrm{TiO}_{2}$-embedded paclitaxel nanoparticles all had growthinhibiting effects on the cell growth, and chitosan-coated $\mathrm{TiO}_{2}$ embedded paclitaxel nanoparticles were the most toxic to the cells $143 \mathrm{~B}$ in a concentration-dependent way. The experimental results show that chitosan-coated $\mathrm{TiO}_{2}$-embedded paclitaxel nanoparticles have good biocompatibility with normal human osteoblasts and a certain growth inhibitory effect on human osteosarcoma cell lines.

\section{Chitosan Increased Antioxidant and Anti-inflammatory Properties}

After the establishment of the osteosarcoma model, the levels of SOD (Figure 4A), CAT (Figure 4B), and GSPx (Figure 4C) 


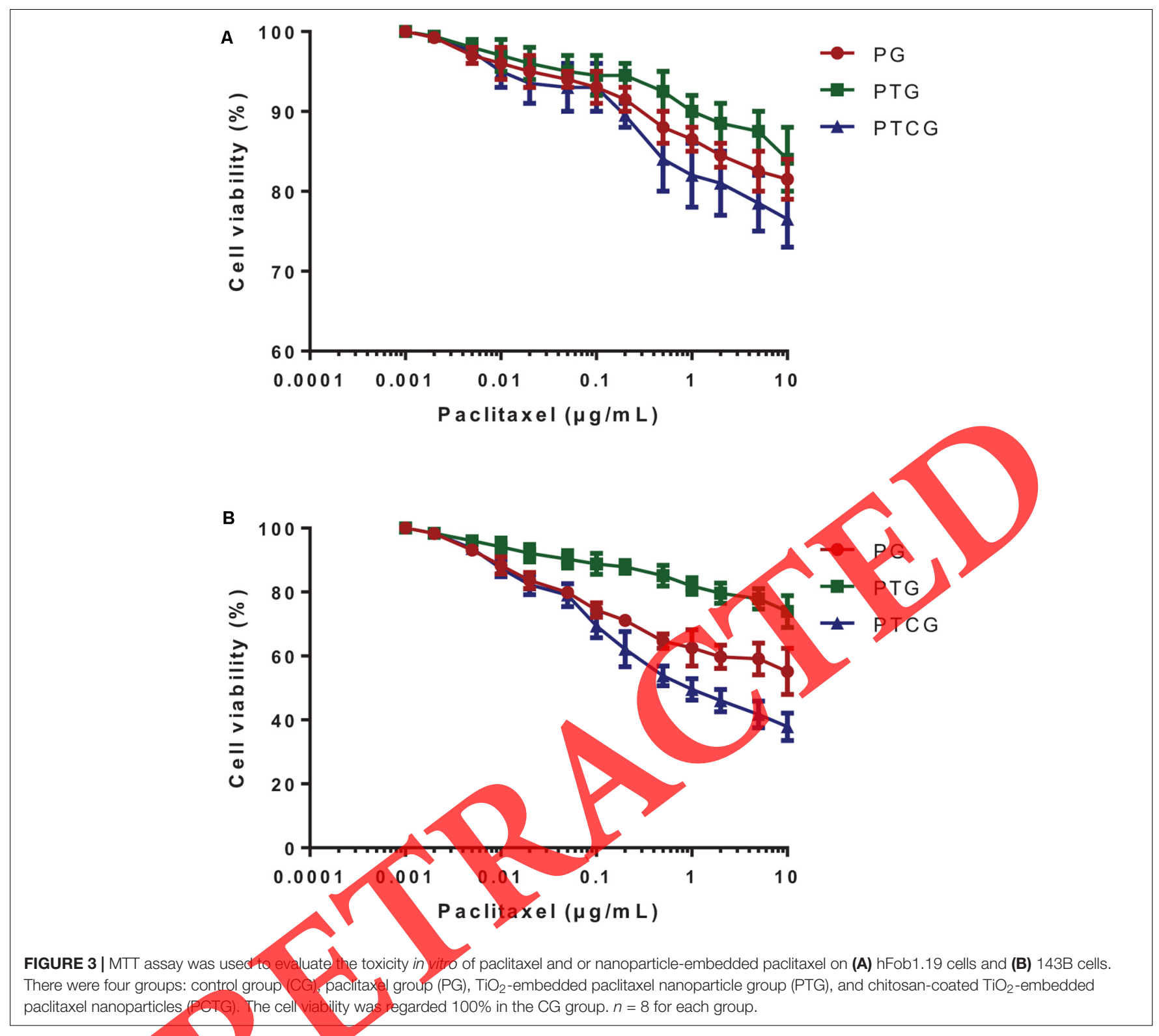

were decreased while MDA (Figure 4D) was increased in the CG group when compared with the other groups $(P<0.05)$. Paclitaxel, $\mathrm{TiO}_{2}$-embedded paclitaxel and chitosan-coated $\mathrm{TiO}_{2}$ embedded paclitaxel nanoparticles treatment increased the levels of SOD (Figure 4A), CAT (Figure 4B), and GSPx (Figure 4C) and reduced the level of MDA (Figure 4D, $P<0.05$ ). Especially, chitosan-coated $\mathrm{TiO}_{2}$-embedded paclitaxel nanoparticles caused the changes of oxidative stress biomarkers higher than those in other groups (Figure 4, $P<0.05$ ).

After the establishment of osteosarcoma model, the levels of TNF $\alpha$ (Figure 5A), IL-1 (Figure 5B), and IL-6 (Figure 5C) increased while the level of IL-10 (Figure 5D) reduced in the CG group when compared with the other groups $(P<0.05)$. Paclitaxel, $\mathrm{TiO}_{2}$-embedded paclitaxel and chitosan-coated $\mathrm{TiO}_{2}$-embedded paclitaxel nanoparticles treatment reduced the level of TNFa (Figure 5A), IL-1 (Figure 5B), and IL-6
(Figure 5C) and increased the level of IL-10 (Figure 5D, $P<0.05)$. Especially, chitosan-coated $\mathrm{TiO}_{2}$-embedded paclitaxel nanoparticles caused the changes in inflammatory cytokines higher than that in the SG group (Figure 5D, $P<0.05$ ). All these results suggest that chitosan increases antioxidant and anti-inflammatory properties.

\section{Evaluation of Antitumor Effect in vivo}

After 14 days of the inoculation of $143 \mathrm{~B}$ cells, the nude mice from different groups were subjected to bioluminescence imaging to confirm that in situ tumors had formed. As shown in Figure 6, each group had obvious fluorescence imaging near the inoculated cells, indicating that the in situ osteosarcoma model was established successfully; the fluorescence area of the tumor site gradually expanded with the nude mice grew in 

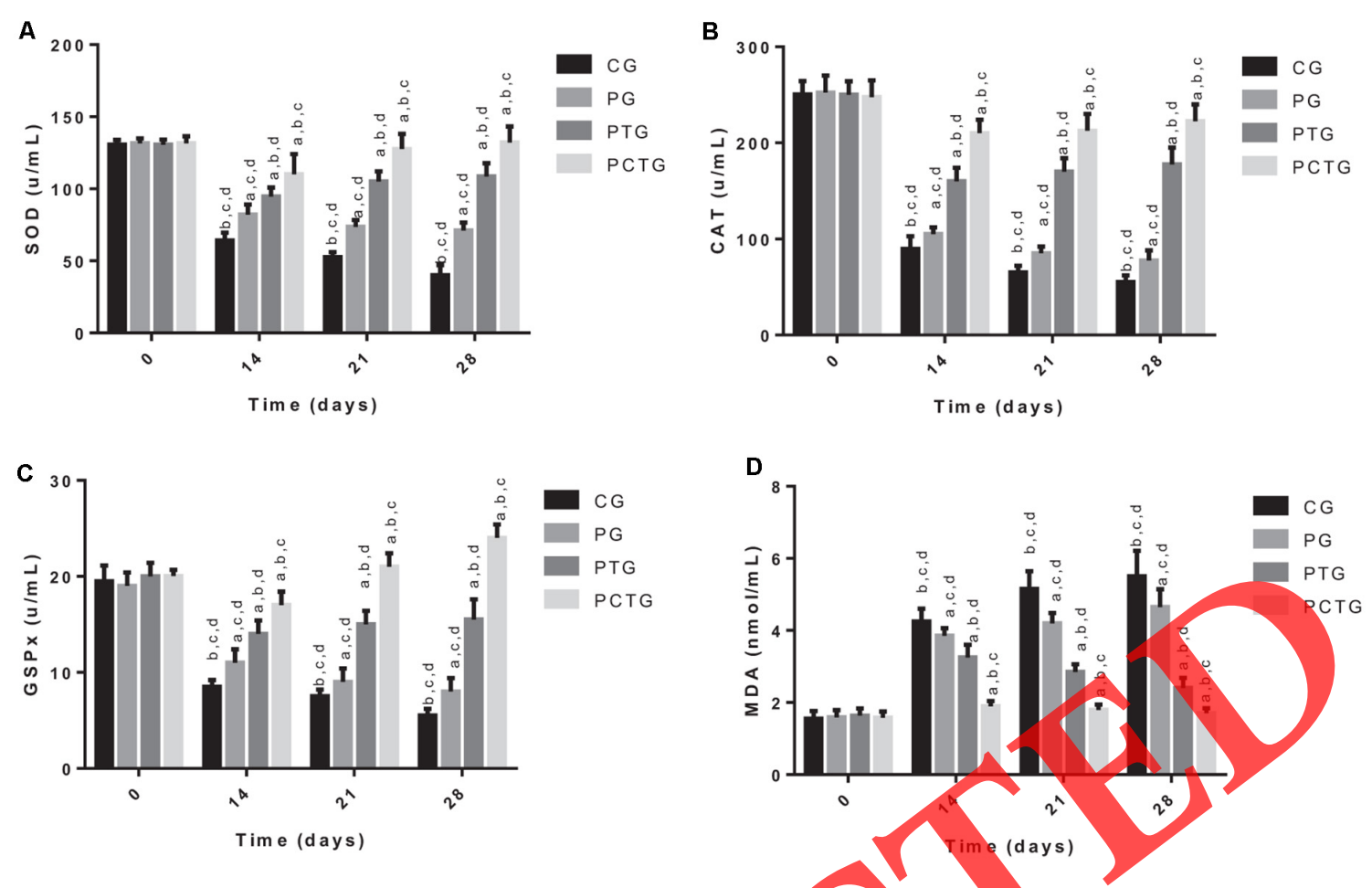

FIGURE 4 | The effects of chitosan on the levels of oxidative stress biomarkers. (A) SOD. (B) CAT. (C) GSPx. (D) MDA. $P=8$ for each group. ${ }^{\text {a } P}<0.05$ vs the CG group, ${ }^{b} P<0.05$ vs the $P G$ group, ${ }^{c} P<0.05$ vs the PTG group and ${ }^{d} P<0.05$ vs the PCTG group.

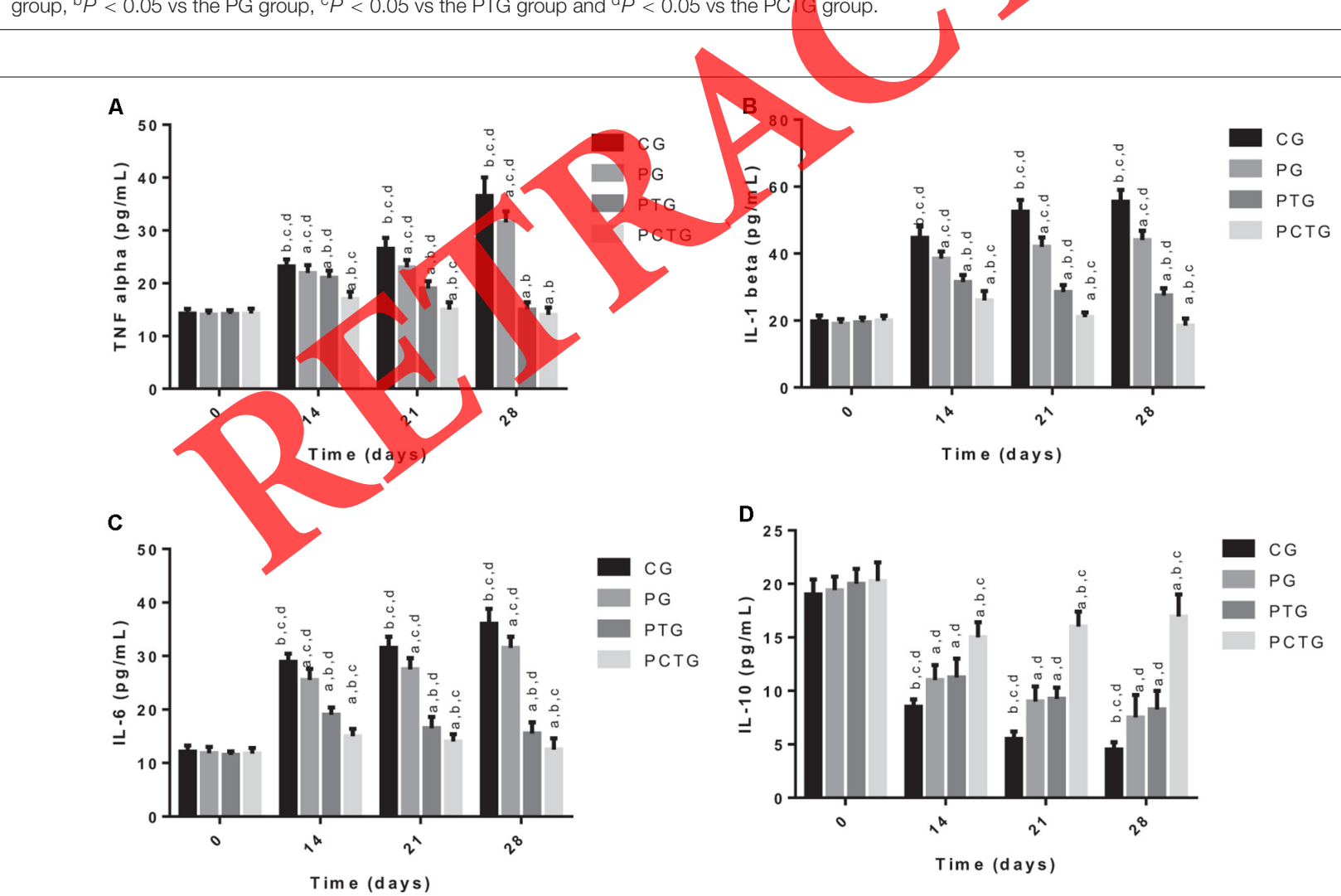

FIGURE 5| The effects of chitosan decoction on the levels of inflammatory cytokines. (A) TNF $\alpha$. (B) IL-1 $\beta$. (C) IL-6. (D) IL-10. $n=8$ for each group. ap $<0.05$ vs the CG group, ${ }^{b} P<0.05$ vs the $P G$ group, ${ }^{c} P<0.05$ vs the PTG group and ${ }^{d} P<0.05$ vs the PCTG group. 


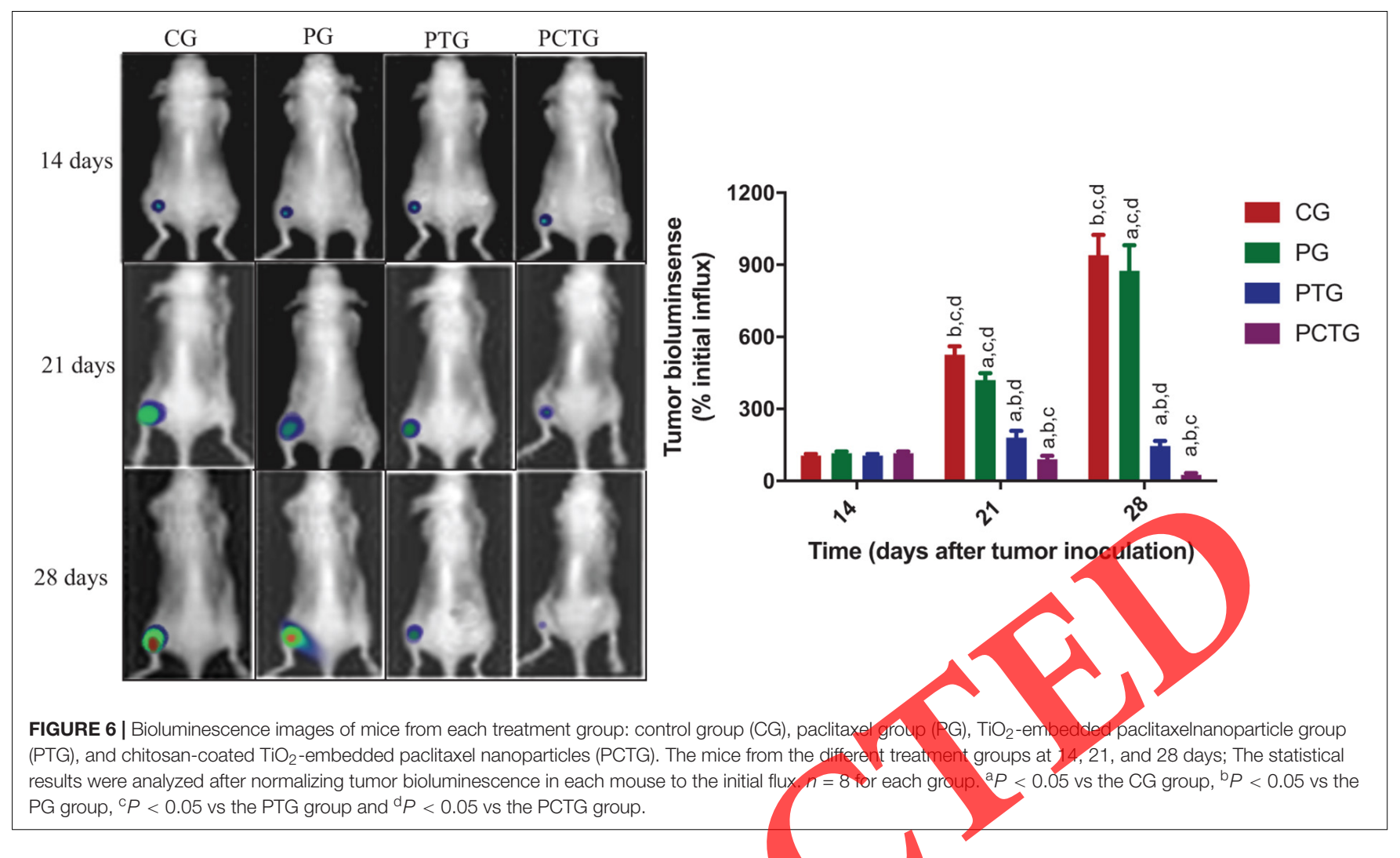

the CG group; after the treatment of chitosan-coated $\mathrm{TiO}_{2}-$ embedded paclitaxel nanoparticles treatment in the PTCG, the fluorescent area of the tumor site gradually reduced, indicating that the nanoparticles had a significant therapeutic effect on osteosarcoma; other experimental groups paclitaxel and $\mathrm{TiO}_{2}$ embedded paclitaxel has a certain treatment on osteosarcoma, but their inhibitory effects on the tumor were lower than that in the PCTG. Further work is needed to confirm these results.

After 28 days of tumor cell noculation, the nude mice were sacrificed and the osteosarcoma tissues were shown in Figure 7. The growth rate of osteosarcoma could be controlled well in the PTCG group $(P<0.05)$. Comparatively, the growth was less controlled in the PG and PTG groups when compared with the PTCG group $(P<0.05)$. Chitosan and $\mathrm{TiO}_{2}$ may have synergistic function in the prevention of osteosarcoma growth. Chitosancoated $\mathrm{TiO}_{2}$-embedded paclitaxel nanoparticles had the slow drug-release ability, which maintained the efficacy of drugs for a longer time and improved the therapeutic results.

\section{Chitosan Increased the Survival Rate of Osteosarcoma Model}

The survival time of the nude mice among different groups was shown in Figure 8. It was found that the survival time of nude mice after intra-tumor injection of chitosan-coated $\mathrm{TiO}_{2}$ embedded paclitaxel nanoparticles was greatly prolonged, while the nude mice in the CG group most died at the 10 weeks. The results suggest that chitosan increased the survival rate of osteosarcoma model.

\section{DISCUSSION}

The synthesis of chitosan-coated nanoparticles meets the concept of green chemistry. Green synthesis of nanoparticles is the present topic of material research (36). This article focused on the construction of paclitaxel self-assembled nanodrugs based on the formation of assemblies between paclitaxel molecules chitosan and $\mathrm{TiO}_{2}$ molecules through hydrophilic/hydrophobic interactions and hydrogen bonding, etc. The addition of chitosan co-precipitated formed an assembly of three molecules because of its biocompatibility. There are modifiable sites on the paclitaxel molecule, which can be amphiphilic with $\mathrm{TiO}_{2}$. To construct a delivery system of hydroxyapatite-chitosan and $\mathrm{TiO}_{2}$-embedded paclitaxel nanoparticles for the treatment of osteosarcoma, chitosan was added after the synthesis of $\mathrm{TiO}_{2}$-embedded paclitaxel nanoparticles. The chitosan-coated $\mathrm{TiO}_{2}$-embedded paclitaxel nanoparticles using the freezedrying technique exerted low density with nice mechanical characteristics. The notable adsorption or water holding activity of chitosan-coated $\mathrm{TiO}_{2}$-embedded paclitaxel nanoparticle was observed in the present experiment. Chitosan-coated $\mathrm{TiO}_{2}$ could be utilized for creating a biocompatible implant with low density. Biocompatible property of chitosan supported cells attachment, proliferation, and mineralization. $\mathrm{TiO}_{2}$ is inert, so the combination of chitosan/ $\mathrm{TiO}_{2}$ can be a good substitute for tissue engineering. Further work is highly demanded to optimize numerous parameters of the chitosan-coated $\mathrm{TiO}_{2}$-embedded paclitaxel nanoparticles without compromising biodegradability and intoxicity. Multidisciplinary approach is also expected to 


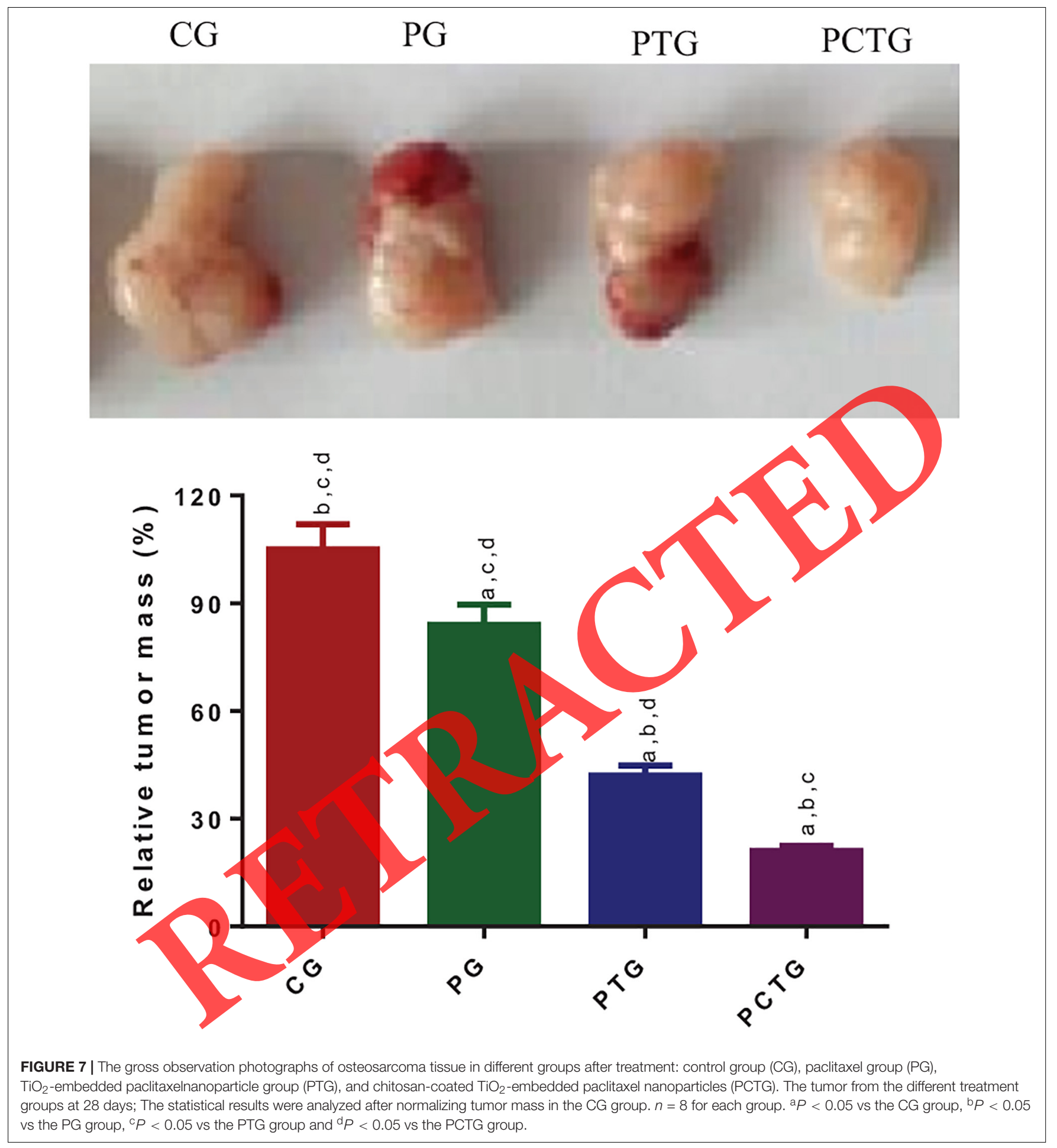

fabricate novel nanoparticles with improved properties. The nanoparticles participated effectively eliminated osteosarcoma cells near bone tissue and prevented its development. Chitosancoated $\mathrm{TiO}_{2}$-embedded paclitaxel nanoparticles had high drugloading efficiency, and paclitaxel release lasts more than 5 days in the in vitro drug sustained-release experiment (data were not shown).
The present findings demonstrate that diameter of $\mathrm{TiO}_{2}-$ embedded paclitaxel nanoparticles increases with the increase in the concentration of chitosan and the increase in the nanoparticle size has a linear relationship with the increase in chitosan concentration (Figure 1, The diameter ranged from $40 \mathrm{~nm}$ to $80 / 120 / 160 / 200 \mathrm{~nm}$ for $1 \% / 2 \% / 3 \% / 4 \%$ chitosancoated $\mathrm{TiO}_{2}$-embedded paclitaxel nanoparticles, respectively. 


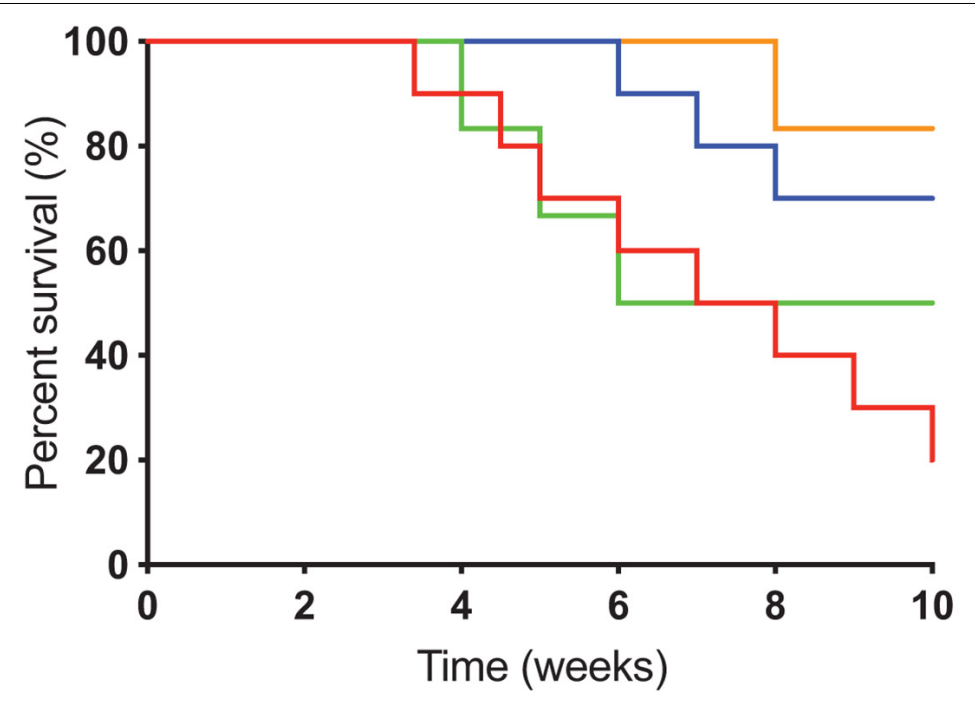

FIGURE 8 | The survival rate of nude mice among different groups. control group (CG), paclitaxel group (PG), TiO 2 -embedded paclitaxelnanoparticle group (PTG), and chitosan-coated $\mathrm{TiO}_{2}$-embedded paclitaxel nanoparticles (PCTG). The tumor from the different treatment groups at 28 days; The statistical results were analyzed after normalizing tumor mass in the CG group. $n=8$ for each group.

The result is consistent with the previous report that the size of chitosan nanoparticles is mostly affected by the chitosan solution concentration, and the increase in nanoparticle size has a linear relationship with the increase in chitosan concentration (37). The size and surface charge of nanoparticles are important properties to understand their implications for possible biological impacts (38). Chitosan nanoparticles have positive charged surfaces and controlled sized according to chitosan concentration, suggesting that chitosan is potential biomaterial for developing nanoparticle-based drug carriers.

In vitro cell experiments showed that chitosan-coated $\mathrm{TiO}_{2}-$ embedded paclitaxel nanoparticles had good biocompatibility and were effective in the prevention of osteosarcoma cell proliferation. The in vivo anti-tumor effect of chitosan-coated $\mathrm{TiO}_{2}$-embedded paclitaxel nanoparticles was evaluated using a nude mouse model of osteosarcoma in situ. Its anti-tumor effect was significant and it prevented tumor metastasis (Figure 6). The paclitaxel self-assembled Nano-drug delivery system was successfully constructed, characterized and showed anti-tumor properties. After the establishment of the osteosarcoma model, the inflammatory and oxidative stress activities were increased (Figures 4, 5), suggesting that inflammatory and oxidative responses were associated with osteosarcoma risk. Chitosancoated $\mathrm{TiO}_{2}$-embedded paclitaxel nanoparticles protected the mice against osteosarcoma development by increasing antioxidant and anti-inflammatory capacities. All these results indicate that chitosan addition improves the biocompatibility, antioxidant and anti-inflammatory properties of $\mathrm{TiO}_{2}$-embedded paclitaxel nanoparticles in the osteosarcoma model. Meanwhile, chitosan addition increases the antitumor activity of $\mathrm{TiO}_{2}$ embedded paclitaxel nanoparticles and the survival rate of the osteosarcoma model.

Nanoparticle therapy has caught enormous interests in the treatment of tumors with multidrug resistance because of its synergistic effects focusing on tumor target cells and reduction of side effects on normal cells (39). Chitosan has been widely used as healthy products in China. The dosage of chitosan less than $1 \mathrm{~g} / \mathrm{kg}$ b.w. will not affeet autonomic or behavioral responses in an animal model (40). The present test showed that $40 \mathrm{mg} / \mathrm{mL}$ chitosan didn't affect the viability of osteoblast cells.

In recent years, the research on chitosan has been widely carried out in drug development and delivery (41-44). It has been documented that chitosan nanoparticles have functions such as better regulation of the immune system and inhibition of tumor growth $(45,46)$. It can not only regulate the microbial metabolism in the intestine, but also regulate the microecological environment $(47,48)$. It can lower blood pressure $(49$, 50), blood lipids, cholesterol (51), and chitosan nanoparticles have anti-oxidation and anti-inflammatory effects (52-54). Chitosan nanoparticles inhibit the growth of tumor cells by inducing cell necrosis and apoptosis $(55,56)$. The nanoparticles also reduce tumor angiogenesis to inhibit tumor cell metastasis $(57,58)$, and may also enhance human immunity. Chitosan should be developed a potential drug-delivering material to prevent osteosarcoma development.

There were some limitations to the present work: this study did not examine the repair of bone defects caused by osteosarcoma after surgery. The self-assembled morphology of chitosan-coated $\mathrm{TiO}_{2}$-embedded paclitaxel nanoparticles was rather special and there was no in-depth study on the presence of paclitaxel in the nanoparticles. The synergistic effect of chitosan and $\mathrm{TiO}_{2}$ and the mechanism of toxicity to osteosarcoma cells were not explored. The methods of chitosan-coated $\mathrm{TiO}_{2}$-embedded paclitaxel in this paper can be further optimized, which can further improve the drug loading. Thermosensitive hydrogels are hoped to be ideal materials for long-term controlling drug release. The mixture of hydrophilic polymer poly (vinyl alcohol) (PVA) and thermosensitive hydrogel 
composed of chitosan and glycerophosphate, can reduce body responses and increase the drug bioavailability (59). The hydrogelation of chitosan displays the phase transition from solution to hydrogel at body temperature $\left(37^{\circ} \mathrm{C}\right)$ and body $\mathrm{pH}$ with $\beta$-GP (60). The temperature responsiveness of the chitosan-coated nanoparticle will promote drug release (61). High-Resolution Transmission Electron Microscopy (HRTEM) has become a routine tool in nanoparticle imaging and structure analysis. Atomic force microscopy can be used to analyze nonideal conditions of these nanoparticles. Thermal characterization of nanomaterials was not undertaken, such as thermogravimetric analysis-differential thermal analysis (TGA-DTA), differential scanning calorimetry (DSC) and Derivative Thermogravimetric Analysis (DTG). These parameters are very important to acquire knowledge of the behavior of these nanoparticles under certain physiological temperature. Unfortunately, all the related work was not explored in the present paper. The current preparation conditions were based on the laboratory level, and further work was still needed to address these important issues.

\section{CONCLUSION}

Chitosan was an important polymer with a wide range of applications in the therapy of osteosarcoma. The microstructure of chitosan-coated $\mathrm{TiO}_{2}$-embedded paclitaxel nanoparticles and $\mathrm{TiO}_{2}$ were consistent with the crystalline of $\mathrm{TiO}_{2}$ and broad phase of chitosan with relevant functional groups in $\mathrm{TiO}_{2}$ nanoparticles. Chitosan-coated $\mathrm{TiO}_{2}$-embedded paclitaxel nanoparticles increased antioxidant and anti-inflammatory, and anti-tumor properties.

\section{REFERENCES}

1. Qu W, Wu J, Li R. Contribution of the GSTP1 gene polymorphism to the development of osteosarcoma in a Chinese population. Genet Mol Res. (2016) 15:gmr8034. doi: 10.4238/gmr15038034

2. Gordon N, Felix K, Daw NC. Aerosolized chemotherapy for osteosarcoma. Adv Exp Med Biol. (2020) 1257:67-73. doi: 10.1007/978-3-030-43032-0_6

3. Garcia MB, Ness KK, Schadley KL. Exercise and physical activity in patients with osteosarcoma and survivors. Adv Exp Med Biol. (2020) 1257:193-207. doi: 10.1007/978-3-030-43032-0_16

4. Sha B, Gao W, Han Y, Wang S, Wu J, Xu F, et al. Potential application of titanium dioxide nanoparticles in the prevention of osteosarcoma and chondrosarcoma recurrence. J Nanosci Nanotechnol. (2013) 13:1208-11. doi: 10.1166/jnn.2013.6081

5. Zhao W, Chen Z, Guan M. Polydatin enhances the chemosensitivity of osteosarcoma cells to paclitaxel. J Cell Biochem. (2019) 120:17481-90. doi: $10.1002 /$ jcb. 29012

6. Zhao L, Bi D, Qi X, Guo Y, Yue F, Wang X, et al. Polydopamine-based surface modification of paclitaxel nanoparticles for osteosarcoma targeted therapy. Nanotechnology. (2019) 30:255101. doi: 10.1088/1361-6528/ab055f

7. Venkatasubbu GD, Ramasamy S, Reddy GP, Kumar J. In vitro and in vivo anticancer activity of surface modified paclitaxel attached hydroxyapatite and titanium dioxide nanoparticles. Biomed Microdevices. (2013) 15:711-26. doi: 10.1007/s10544-013-9767-7

8. Chatterjee S, Ooya T. Hydrophobic nature of methacrylate-POSS in combination with 2-(Methacryloyloxy)ethyl phosphorylcholine for enhanced solubility and controlled release of paclitaxel. Langmuir. (2019) 35:1404-12. doi: 10.1021/acs.langmuir.8b01588

\section{DATA AVAILABILITY STATEMENT}

The raw data supporting the conclusions of this article will be made available by the authors, without undue reservation.

\section{ETHICS STATEMENT}

The animal study was reviewed and approved by Institutional Animal Care and Use Committee of Jilin University, IACUC, No. 2019JLU23D.

\section{AUTHOR CONTRIBUTIONS}

YQ and JZ conceived and designed the experiments. MK and $\mathrm{XC}$ performed the experiments and analyzed data. YQ and JZ wrote the manuscript. All authors contributed to the article and approved the submitted version.

\section{FUNDING}

This work was supported by the Project of Jilin Science and Technology (NO. 20170204031YY).

\section{SUPPLEMENTARY MATERIAL}

The Supplementary Material for this article can be found online at: https://www.frontiersin.org/articles/10.3389/fonc. 2020.577280/full\#supplementary-material

9. Zhong T, Hao YL, Yao X, Zhang S, Duan XC, Yin YF, et al. Effect of XlogP and hansen solubility parameters on small molecule modified paclitaxel anticancer drug conjugates self-assembled into nanoparticles. Bioconjug Chem. (2018) 29:437-44. doi: 10.1021/acs.bioconjchem.7b00767

10. Saravanan S, Vimalraj S, Thanikaivelan P, Banudevi S, Manivasagam G. A review on injectable chitosan/beta glycerophosphate hydrogels for bone tissue regeneration. Int J Biol Macromol. (2018) 121:38-54. doi: 10.1016/j.ijbiomac. 2018.10.014

11. Azizian S, Hadjizadeh A, Niknejad H. Chitosan-gelatin porous scaffold incorporated with Chitosan nanoparticles for growth factor delivery in tissue engineering. Carbohydr Polym. (2018) 202:315-22. doi: 10.1016/j.carbpol. 2018.07.023

12. Yang T, Feng J, Zhang Q, Wu W, Mo H, Huang L, et al. 1-Carnitine conjugated chitosan-stearic acid polymeric micelles for improving the oral bioavailability of paclitaxel. Drug Deliv. (2020) 27:575-84. doi: 10.1080/10717544.2020. 1748762

13. Kaur N, Mathur P, Yadav P, Chakraborty S, Shanavas A. Glycol chitosan in situ coating on PLGA nanoparticle curtails extraneous paclitaxel precipitates and imparts protein corona independent hemocompatibility. Carbohydr Polym. (2020) 237:116170. doi: 10.1016/j.carbpol.2020.116170

14. Han Y, Liang N, Yan P, Kawashima Y, Cui F, Sun S. A chitosan-based micellar system as nanocarrier for the delivery of paclitaxel. Polymers (Basel). (2020) 12:380. doi: $10.3390 /$ polym 12020380

15. Zima A. Hydroxyapatite-chitosan based bioactive hybrid biomaterials with improved mechanical strength. Spectrochim Acta A Mol Biomol Spectrosc. (2018) 193:175-84. doi: 10.1016/j.saa.2017.12.008

16. Ullah S, Zainol I, Chowdhury SR, Fauzi MB. Development of various composition multicomponent chitosan/fish collagen/glycerin 3D porous 
scaffolds: effect on morphology, mechanical strength, biostability and cytocompatibility. Int J Biol Macromol. (2018) 111:158-68. doi: 10.1016/j. ijbiomac.2017.12.136

17. Freier T, Koh HS, Kazazian K, Shoichet MS. Controlling cell adhesion and degradation of chitosan films by $\mathrm{N}$-acetylation. Biomaterials. (2005) 26:58728. doi: 10.1016/j.biomaterials.2005.02.033

18. Chouirfa H, Bouloussa H, Migonney V, Falentin-Daudré C. Review of titanium surface modification techniques and coatings for antibacterial applications. Acta Biomater. (2019) 83:37-54. doi: 10.1016/j.actbio.2018.10.036

19. Shetti NP, Bukkitgar SD, Reddy KR, Reddy CV, Aminabhavi TM. Nanostructured titanium oxide hybrids-based electrochemical biosensors for healthcare applications. Colloids Surfaces B Biointerfaces. (2019) 178:385-94. doi: 10.1016/j.colsurfb.2019.03.013

20. Grande Tovar CD, Castro JI, Valencia CH, Zapata PA, Solano MA, López EF, et al. Synthesis of chitosan beads incorporating graphene oxide/titanium dioxide nanoparticles for in vivo studies. Molecules. (2020) 25:2308. doi: $10.3390 /$ molecules 25102308

21. Wen JF, Jiang YQ, Li C, Dai XK, Wu T, Yin WZ. LncRNA-XIST promotes the oxidative stress-induced migration, invasion, and epithelial-to-mesenchymal transition of osteosarcoma cancer cells through miR-153-SNAI1 axis. Cell Biol Int. (2020). doi: 10.1002/cbin.11405

22. Yang S, Wu C, Wang L, Shan D, Chen B. Pretreatment inflammatory indexes as prognostic predictors for survival in osteosarcoma patients. Int J Clin Exp Pathol. (2020) 13:515-24.

23. Zhang L, Xu X, Jiang T, Wu K, Ding C, Liu Z, et al. Citrus aurantium naringenin prevents osteosarcoma progression and recurrence in the patients who underwent osteosarcoma surgery by improving antioxidant capability. Oxid Med Cell Longev. (2018) 2018:8713263. doi: 10.1155/2018/8713263

24. Poradowski D, Obminska-Mrukowicz B. Effect of selected nonsteroidal antiinflammatory drugs on the viability of canine osteosarcoma cells of the D-17 Line: in vitro studies. J Vet Res. (2019) 63:399-403. doi: 10.2478/jvetres-20190051

25. Sheorain J, Mehra M, Thakur R, Grewal S, Kumari S. In vitro antiinflammatory and antioxidant potential of thymol loaded bipolymeric (tragacanth gum/chitosan) nanocarrier. Int J Biol Macromol. (2019) 125:106974. doi: 10.1016/j.ijbiomac.2018.12.095

26. Ali SS, Kenawy ER, Sonbol FI, Sun J, Al-Etewy M, Ali A, et al. Pharmaceutical potential of a novel chitosan derivative schiff base with special reference to antibacterial, anti-biofilm, antioxidant, anti-inflammatory, hemocompatibility and cytotoxic activities. Pharm Res. (2018) 36:5. Coi. 10.1007/S1/095-018 2535- $\mathrm{x}$

27. Eskandari N, Nabiyouni G, Masoumi S, Ghanbari D Preparation of new magnetic and photo-catalyst $\mathrm{CoFe} 2 \mathrm{O} 4-\mathrm{Sr}$ IiO3 3 perovskite nanocomposite for photo-degradation of toxic dyes under short time visible irradiation. Composites Part B Eng. (2019)176:107343. doi: 10.1016/j.compositesb.2019. 107343

28. Kiani A, Nabiyouni G, Masoumi S, Ghanbari D. A novel magnetic MgFe2O4$\mathrm{MgTiO} 3$ perovskite nanocomposite: rapid photo-degradation of toxic dyes under visible irradiation. Composites Pary B Eng. (2019) 175:107080. doi: 10.1016/j.compositesb.2019.107080

29. Moradi B, Nabiyouni G, Ghanbari D. Rapid photo-degradation of toxic dye pollutants: green synthesis of mono-disperse $\mathrm{Fe} 3 \mathrm{O} 4-\mathrm{CeO} 2$ nanocomposites in the presence of lemon extract. J Mater Sci Mater Electron. (2018) 29:1106580. doi: 10.1007/s10854-018-9189-7

30. Etminan M, Nabiyouni G, Ghanbari D. Preparation of tin ferrite-tin oxide by hydrothermal, precipitation and auto-combustion: photo-catalyst and magnetic nanocomposites for degradation of toxic azo-dyes. J Mater Sci Mater Electron. (2018) 29:1766-76. doi: 10.1007/s10854-017-8085-x

31. Naghikhani R, Nabiyouni G, Ghanbari D. Simple and green synthesis of CuFe $2 \mathrm{O} 4-\mathrm{CuO}$ nanocomposite using some natural extracts: photo-degradation and magnetic study of nanoparticles. J Mater Sci Mater Electron. (2018) 29:4689-703. doi: 10.1007/s10854-017-8421-1

32. Nabiyouni G, Ghanbari D. Simple preparation of magnetic, antibacterial and photo-catalyst NiFe2O4@ TiO2/Pt nanocomposites. J Nanostruct. (2018) 8:408-16.

33. Pookmanee P, Phanichphant S. Titanium dioxide powder prepared by a sol-gel method. J Ceram Process Res. (2009) 10:167-70.
34. Mosialou I, Shikhel S, Liu JM, Maurizi A, Luo N, He Z, et al. MC4Rdependent suppression of appetite by bone-derived lipocalin 2. Nature. (2017) 543:385-90. doi: 10.1038/nature21697

35. van Asperen J, van Tellingen O, van der Valk MA, Rozenhart M, Beijnen $\mathrm{JH}$. Enhanced oral absorption and decreased elimination of paclitaxel in mice cotreated with cyclosporin A. Clin Cancer Res. (1998) 4:2293-7.

36. Joulaei M, Hedayati K, Ghanbari D. Investigation of magnetic, mechanical and flame retardant properties of polymeric nanocomposites: green synthesis of $\mathrm{MgFe} 2 \mathrm{O} 4$ by lime and orange extracts. Composites Part B Eng. (2019) 176:107345. doi: 10.1016/j.compositesb.2019.107345

37. Gan Q, Wang T, Cochrane C, McCarron P. Modulation of surface charge, particle size and morphological properties of chitosan-TPP nanoparticles intended for gene delivery. Colloids Surfaces B Biointerfaces. (2005) 44:65-73. doi: 10.1016/j.colsurfb.2005.06.001

38. Lundqvist M, Stigler J, Elia G, Lynch I, Cedervall T, Dawson KA. Nanoparticle size and surface properties determine the protein corona with possible implications for biological impacts. Proc Natl Acad Sci USA. (2008) 105:1426570. doi: $10.1073 /$ pnas. 0805135105

39. Su S-H, Chang M-Y, He C-P. Social support, unstable angina, and stroke as predictors of depression in patients with coronary heart disease: erratum. $J$ Cardiovasc Nurs. (2018) 33:201. doi: 10.1097/ jen.0000000000000501

40. Fernandes JC, Spindola H, de Sousa V, Santos-Silva A, Pintado ME, Malcata FX, et al. Anti-inflammatory activity of chitooligosaccharides in vivo. Mar Drugs. (2010) 8:1763-8. doi: 103390/md80617

41. Khatun B, Banik N, Hussain A, Ranteke A, Maji T Genipin crosslinked curcumin loaded chitosan/montmorillonite K-10 (MMT) nanoparticles for controlled drug delivery applications. J Microencapsul. (2018) 35:439-53. doi: $10.1080 / 02652048.2018 .1524524$

42. Khan MIH, An X, Dai L, Li H, Khan A, Ni Y. Chitosan-based polymer matrix for pharmaceutical excipients and arug delivery. Curr Med Chem. (2018) 26:2502-13. doi: 10.2174/0929867325666180927100817

43. Perrone M, Lopalco A, Lopedota A, Cutrignelli A, Laquintana V, Franco M, et al. S-preactivated thiolated glycol chitosan useful to combine mucoadhesion and drug delivery, Eur J Pharm Biopharm. (2018) 132:103-11. doi: 10.1016/j. ejpb.2 2018

44. Rahimi S, Khoee S, Ghandi M. Development of photo and $\mathrm{pH}$ dual crosslinked coumarm-containing chitosan nanoparticles for controlled drug release. Carbohydr Polym. (2018) 201:236-45. doi: 10.1016/j.carbpol.2018.08.074

Daneshmandi S, Pourfathollah AA, Forouzandeh-Moghaddam M. Enhanced CD40 and ICOSL expression on dendritic cells surface improve antitumor immune responses; effectiveness of mRNA/chitosan nanoparticles. Immunopharmacol Immunotoxicol. (2018) 40:375-86. doi: 10.1080/08923973. 2018.1510959

46. Li J, Liu P. One-pot fabrication of $\mathrm{pH} /$ reduction dual-stimuli responsive chitosan-based supramolecular nanogels for leakage-free tumor-specific DOX delivery with enhanced anti-cancer efficacy. Carbohydr Polym. (2018) 201:583-90. doi: 10.1016/j.carbpol.2018.08.102

47. Eshrati M, Amadei F, Van de Wiele T, Veschgini M, Kaufmann S, Tanaka M. Biopolymer-based minimal formulations boost viability and metabolic functionality of probiotics Lactobacillus rhamnosus GG through gastrointestinal passage. Langmuir. (2018) 34:11167-75. doi: 10.1021/acs. langmuir.8b01915

48. Bepeyeva A, de Barros JMS, Albadran H, Kakimov AK, Kakimova Z, Charalampopoulos D, et al. Encapsulation of Lactobacillus casei into calcium pectinate-chitosan beads for enteric delivery. J Food Sci. (2017) 82:2954-9. doi: 10.1111/1750-3841.13974

49. Huang H, Zou Y, Chi H. Quantitative assessment of the effects of chitosan intervention on blood pressure control. Drug Des Devel Ther. (2018) 12:67-75. doi: $10.2147 /$ dddt.s 148064

50. Allaert FA. Effect of $\mathrm{NaCl}+$ Chitosan $3 \%$ vs. $\mathrm{NaCl}$ on high blood pressure parameters of healthy volunteers with prehypertension. Minerva Cardioangiol. (2017) 65:563-76.

51. Mosallanejad B, Avizeh R, Razi Jalali M, Pourmahdi M. Comparative evaluation between chitosan and atorvastatin on serum lipid profile changes in hyperlipidemic cats. Iran J Vet Res. (2016) 17:36-40.

52. Hastak V, Bandi S, Kashyap S, Singh S, Luqman S, Lodhe M, et al. Antioxidant efficacy of chitosan/graphene functionalized superparamagnetic iron oxide 
nanoparticles. J Mater Sci Mater Med. (2018) 29:154. doi: 10.1007/s10856018-6163-0

53. Shahid Ul I, Butola BS, Roy A. Chitosan polysaccharide as a renewable functional agent to develop antibacterial, antioxidant activity and colourful shades on wool dyed with tea extract polyphenols. Int J Biol Macromol. (2018) 120(Pt B):1999-2006. doi: 10.1016/j.ijbiomac.2018.09.167

54. Vanden Braber NL, Novotny Nunez I, Bohl L, Porporatto C, Nazar FN, Montenegro MA, et al. Soy genistein administered in soluble chitosan microcapsules maintains antioxidant activity and limits intestinal inflammation. J Nutr Biochem. (2018) 62:50-8. doi: 10.1016/j.jnutbio.2018. 08.009

55. Saravanakumar K, Jeevithan E, Chelliah R, Kathiresan K, Wen-Hui W, Oh $\mathrm{DH}$, et al. Zinc-chitosan nanoparticles induced apoptosis in human acute T-lymphocyte leukemia through activation of tumor necrosis factor receptor CD95 and apoptosis-related genes. Int J Biol Macromol. (2018) 119:1144-53. doi: 10.1016/j.ijbiomac.2018.08.017

56. Wang T, Hou J, Su C, Zhao L, Shi Y. Hyaluronic acid-coated chitosan nanoparticles induce ROS-mediated tumor cell apoptosis and enhance antitumor efficiency by targeted drug delivery via CD44. J Nanobiotechnol. (2017) 15:7. doi: 10.1186/s12951-016-0245-2

57. Kim GH, Won JE, Byeon Y, Kim MG, Wi T, Lee JM, et al. Selective delivery of PLXDC1 small interfering RNA to endothelial cells for anti-angiogenesis tumor therapy using CD44-targeted chitosan nanoparticles for epithelial ovarian cancer. Drug Deliv. (2018) 25:1394-402. doi: 10.1080/10717544.2018. 1480672
58. Jin H, Pi J, Yang F, Wu C, Cheng X, Bai H, et al. Ursolic acid-loaded chitosan nanoparticles induce potent anti-angiogenesis in tumor. Appl Microbiol Biotechnol. (2016) 100:6643-52. doi: 10.1007/s00253-016-7360-8

59. Sun J, Jiang G, Wang Y, Ding F. Thermosensitive chitosan hydrogel for implantable drug delivery: blending PVA to mitigate body response and promote bioavailability. J Appl Polymer Sci. (2012) 125:2092-101. doi: 10. 1002/app.36297

60. Han HD, Seo DH, Kim TW, Shin BC, Choi HS. Preparation and biodegradation of thermosensitive chitosan hydrogel as a function of $\mathrm{pH}$ and temperature. Macromol Res. (2004) 12:507-11. doi: 10.1007/bf03218435

61. Lee CF, Wen CJ, Lin CL, Chiu WY. Morphology and temperature responsiveness-swelling relationship of poly (N-isopropylamide-chitosan) copolymers and their application to drug release. J Polymer Sci Part A Polymer Chem. (2004) 42:3029. doi: 10.1002/pola.20085

Conflict of Interest: The authors declare that the research was conducted in the absence of any commercial or financial relationships that could be construed as a potential conflict of interest.

Copyright (c) 2020 Qu, Kang, Cheng and Zhao. This is an open-access article distributed under the terms of the Creative Commons Attribution License (CC BY). The use, distribution or reproduction in other forums is permitted, provided the original author(s) and the copyright owner(s) are credited and that the original publication in this journal is cited, in accordance with accepted academic practice. No use, distribution or reproduction is permitted which does not comply with these terms.

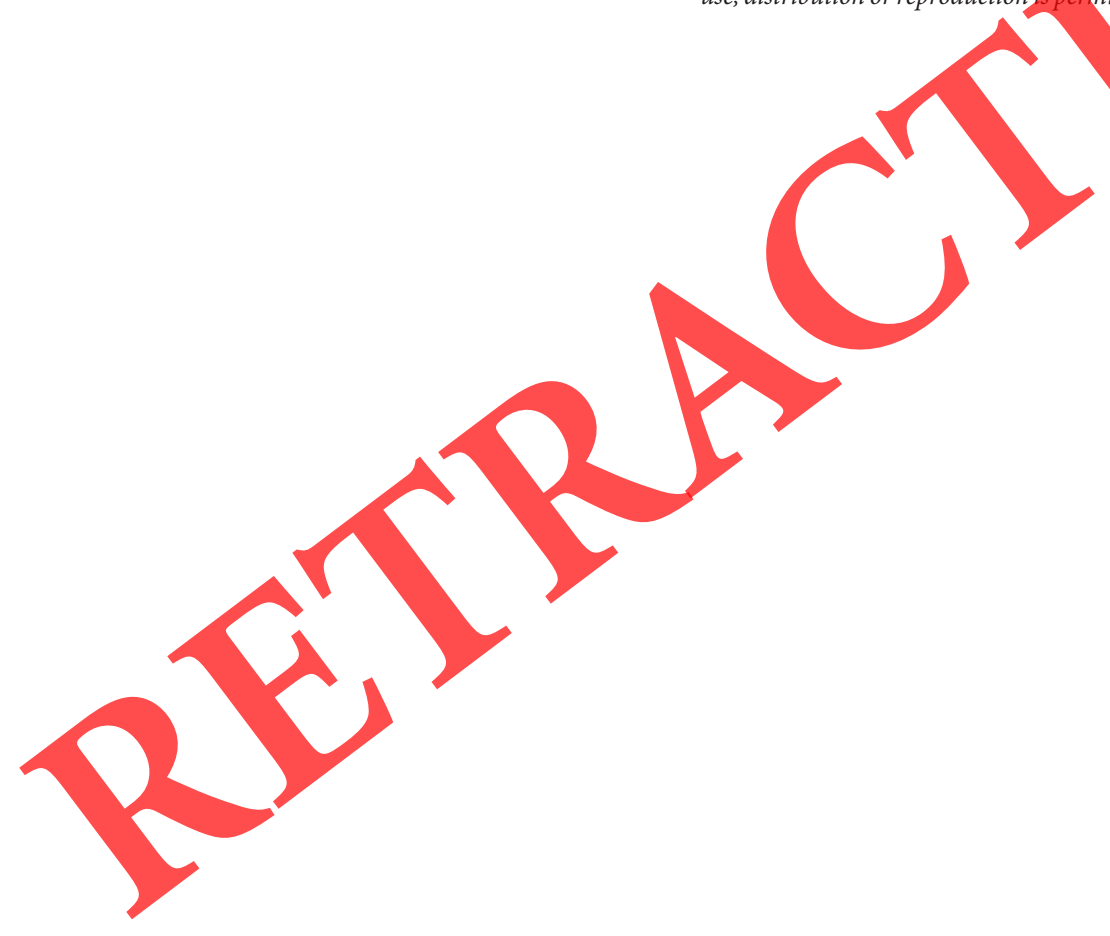

